\title{
ASSESSMENT OF PERFORMANCE MEASUREMENT FRAMEWORKS SUPPORTING THE IMPLEMENTATION OF LEAN CONSTRUCTION
}

\author{
Alexandros Hatzigeorgiou ${ }^{1}$ and Odysseas Manoliadis ${ }^{2}$
}

\begin{abstract}
Construction companies can perceive significant benefits of Lean Construction management, although cannot clearly identify the extent and origin of the obtained benefits. Frameworks, consisting structured tools suitable for business management, find wide application in the field of Performance Measurement, in most of the industries. The role of contemporary, process-oriented, Performance Measurement frameworks, like the European Foundation for Quality Management Excellence Model, the Balanced Scorecard and Key Performance Indicators, in supporting Lean Construction is examined in this study. The contribution of Performance Measurement Systems developed upon such frameworks, in the implementation of basic Lean Construction principles, like waste/variability reduction, operation simplification and benchmarking, is demonstrated by reviewing a number of related studies from the literature and identifying their basic characteristics regarding the adopted Performance Measurement frameworks and the involved Lean Construction principles. The presented studies indicate that the use of these frameworks, and especially Key Performance Indicators, can assist the application of specific Lean Construction principles, and most of all benchmarking.
\end{abstract}

Keywords: lean construction principles, performance measurement frameworks.

\section{INTRODUCTION}

Performance Measurement (PM) is an integral part of management, assisting organizations to establish challenging and feasible goals and objectives and to connect them with improvements. PM is a well explored subject in literature and has gained significant attention during the 1990s among academics and professionals in most of the economy's sectors, followed by a plethora of published articles, described by Neely (1999) as "revolution". It had a profound impact on the construction industry too, where more and more construction engineering organizations started adopting Performance Measurement Systems (PMSs), over the past two decades (Bassioni et al. 2004).

Traditional PMSs, depending solely on financial measures, has been strongly criticized as strictly results-oriented and backward focused (Lantelme and Formoso 2000), since they are based on lagging indicators describing the outcomes of managerial actions or decisions only after they occur. This widespread dissatisfaction, climaxing in the late 1970s and early 1980s, has driven the construction industry to shift to modern methods of PM, with the use of process-oriented, leading measures, aiming to give early warnings and identify barriers and potential problems in the implementation of strategy and the attainment of goals and objectives (Costa et al. 2006).

\footnotetext{
${ }^{1}$ Civil Engineer A.U.Th., M.B.A. U.O.M., MSc "Engineering Project Management", School of Science and Technology, Hellenic Open University, Patra, Greece, alexhatz1973@gmail.com

${ }_{2}^{2}$ Associate Professor, Department of Civil Engineering, Democritus University of Thrace, Xanthi, Greece, omanolia@civil.duth.gr
} 
Lean Production (LP) emerged in the middle 1980s as a breakthrough production philosophy, aiming at the designing of a production system to deliver a custom product instantly on order, with the less possible intermediate inventories (Howell 1999). The seminal technical report of Koskela (1992), introducing the Transformation-Flow-Value generation model, was the first consideration of the application of concepts of LP in construction, giving birth to the term Lean Construction (LC). Koskela summarized a number of heuristic principles for the improvement of flow processes in production. On the top of the list, described as the core principle of LP, is the reduction of non valueadding activities from the production process, called waste, and the efficiency increase of value-adding ones. Reviewing the construction production as a combination of conversion and flow processes, waste reduction consists probably the central idea of LC. An associated principle with waste removal is variability reduction, expressed as unreliable workflow between processes, which can decrease the amount of non value-adding activities and increase customer satisfaction. In LC the issue of variability is usually addressed in terms of construction labour productivity (Thomas et al. 2002). Operations simplification is another critical LP principle, accomplished by minimizing the number of steps or parts involved in the production process, which can find application in construction too. Finally, the well-known benchmarking, a systematic process of comparing and measuring the organization's performance against other similar ones in key business activities can be considered as a general principal related both to LP and LC issues. In construction, benchmarking can be implemented with the use of indices of construction labour productivity (Manoliadis 2011).

The present paper is aiming to stress the contribution of the use of contemporary PMSs in construction in the successful implementation of business strategies like LC, by assisting the employment of the above principles. In doing so, the paper is first reviewing the most widely implemented PM frameworks applied in construction and is then presenting and commending on a number of characteristic studies of PMSs, developed for construction firms and projects, which support the use of such principles.

\section{CONTEMPORARY PERFormanCE MEASUREMENT FrameWORKS APPLIED IN CONSTRUCTION}

After the gradual abundance of traditional PMSs since the 1980s, a number of models and frameworks have been evolved and developed for PM, trying to bridge the gap between financial and non-financial measures. Nevertheless, not all of them experienced wide implementation within the construction industry. According to a number of researchers (Bassioni et al. 2004; Yang et al. 2010), the most frequently used PM frameworks in construction are the European Foundation for Quality Management (EFQM) Excellence Model, the Balanced Scorecard (BSC) and the Key Performance Indicators (KPIs), presented briefly in the next sections.

\subsection{The European Foundation for Quality Management (EFQM) Excellence Model}

One of the most utilized quality-based management models is the EFQM Excellence Model, a non-prescriptive framework developed in 1989 in Europe by the EFQM, a membership based, non-profit organization. It has emerged as a major tool in the development of continuous business improvement, aiming to improve performance and to enable the assessment of excellence, by measuring and upgrading the overall quality of an 
organization, based on eight fundamental concepts of excellence (EFQM 1999): Results Orientation, People Development \& Involvement, Customer Focus, Continuous Learning Innovation \& Improvement, Leadership \& Constancy of Purpose, Partnership Development, Management by Process \& Facts and Public Responsibility.

The EFQM Excellence Model consists of nine criteria, intrinsically linked, requiring measurement of results, that can be used to identify dimensions of PM: i) five enabler's criteria, dealing with how the various activities are undertaken and representing the management of the organization and ii) four sets of results criteria, focusing on what results an organization have achieved. The model starts on the left-hand side with Leadership, essential for any action or decision of an organization, which decides upon the organization's Policy \& Strategies, utilizing the capabilities of its People and deploying its Partnerships \& Resources. Next, the organization's Processes which will deliver the desired Customer Results are defined, affecting also the employees of the organization (People Results) and the society in general (Society Results). These results will in turn determine the organization's Key Performance Results. The model is further devised to be used as a self-assessment tool (Beatham et al. 2004). Despite its original mission as a business quality and excellence model, the EFQM Excellence Model has been used ever since as a PM framework (Bassioni et al. 2004) and, although developed generically, has been adopted by many construction companies in the last decade.

\subsection{The Balanced Scorecard (BSC)}

Kaplan and Norton (1992) introduced the BSC as a new PMS, characterizing it as a comprehensive framework that can translate a company's vision and strategy into a coherent and linked series of measures and sub-measures. BSC allows an organization to measure and evaluate its performance through four distinct perspectives: i) Financial Perspective, monitoring the organization's financial performance, with the use of typical financial and accounting ratios, such as Current Ratio, Net Profit, ROI, ROA, etc. ii) Customer Perspective, looking at the organization through the eyes of its customers, involving specific measures that reflect factors critical to customers such as delivery time, quality, service, and cost. iii) Internal Process Perspective, reporting on the efficiency of internal processes and procedures such as cycle time, inventory management, productivity control and logistics. iv) Learning and Growth Perspective, reflecting the commitment of the organization to grow and adapt to change by measuring its ability to innovate, improve and learn. A proper BSC should consist of both core outcome measures (lagging indicators) as objectives and performance drivers (leading indicators) as sub-measures of these outcomes (Kaplan and Norton 1996).

Although BSC was initially introduced to serve as the basis of a typical PMS, it was further promoted as a strategic management system (Kaplan and Norton 1996) with an important underlying principle, organized on a cause-and-effect relationship base between the four perspectives. Innovation and learning will be used for the development of new technologies and processes that can be implemented to decrease costs and increase efficiencies in the internal business perspective, providing higher value and satisfaction to the customer, which will in turn produce improved financial results. Yang et al. (2010) considered BSC as the most frequently used PM framework, in the organizational level, in construction industry.

\subsection{Key Performance Indicators (KPIs)}

During the 1990s two landmark reports, the first by Sir Michael Latham (1994) and the second by Sir John Egan (1998), were published, setting specific targets for performance 
level improvement in the construction industry. In response to these two reports, the Construction Best Practice Program (CBPP), a government funded organization, was established in the U.K., identifying Key Performance Indicators (KPIs) as the measures of the performance of the process critical to its success and launching the KPI Programme in 1998. CBPP developed in 2000 a first set of 10 headline KPIs, serving as a measure of the overall state of health of a company, roughly classified into three categories: economic, respect for people and environment, and divided into project and company level. These headline KPIs were further distinguished as operational and diagnostic KPIs. CBPP was soon acknowledged as the leading organization in the production of KPIs for the construction industry and its merging with the "Rethinking Construction" movement created in 2004 the Constructing Excellence (CE) Programme of the U.K (CE 2006).

In the case of the U.S, the importance of performance assessment in increasing competitiveness and growth was acknowledged in the early 1990s. The Benchmarking \& Metrics Programme (B\&MP) of the Construction Industry Institute (CII) is another widely known construction PM initiative, aiming to provide the construction industry with a common set of metric definitions and performance norms and to illuminate and quantify the use and value of best practices (Costa et al. 2006). B\&MP reported a first performance data collection in 1996 and its current review includes a set of indicators classified in the categories of budgeted/actual costs, planned/actual schedule, facility capacity, project outcomes, accident data and project impact factors. Its goal is to set performance standards in the construction industry using a consistent PM algorithm and to develop assessment tools in order to promote construction performance (CII 2001).

KPI models have been widely applied in the construction industry, aiming to eliminate inefficiency and maximize cost effectiveness and productivity (Cha and Kim 2011), yet significantly criticised as lagging measures, inappropriate for decision making, performance improvement and change opportunities (Bassioni et al., 2004).

\section{CONTRibution ANd APplications Of PERFormance MEASUREMENT FRAMEWORKS IN LEAN CONSTRUCTION}

Lantelme and Formoso (2000) pointed out the important role PM plays in process control and LP systems in general, providing process transparency and assisting the conversion of usually invisible attributes to visible. Consequently, the use of appropriate and welldesigned PMSs, for supporting the successful implementation of LC, has been emphasised by many researchers. According to Alarcón et al. (2001), traditional control systems focus their attention in conversion activities ignoring flow ones, therefore most of the nonvalue-adding activities become invisible. Sarhan and Fox (2013) argued that one of the critical factors for the poor application of lean principles in construction is the failure to use appropriate process oriented PMSs.

Despite the huge number of published articles in the field of PM in construction, few of them can be accounted for explicitly supporting the application of the four basic LC principles, discussed earlier. Some of the most significant and cited studies, published in major construction management journals, are briefly presented in the next section.

\subsection{Related studies}

Cox et al. (2003) acknowledged the necessity of identifying common indicators for construction executives and managers in measuring projects' performance and investigated management perceptions of quantitative and qualitative KPIs utilized in the 
construction industry. They generated an initial set of perceived KPIs, through literature research, and conducted a survey in order to administer them to the construction industry. Performing statistical analysis of the collected responses and trying to identify common KPIs by construction sector and management or experience level, they argued that the reported KPIs differ according to management's perspectives but identified six top rated indicators, including: quality control, on-time completion, cost, safety, cost/unit and units/man-hours, reported as the most useful by every construction sector.

Beatham et al. (2004) reviewed and appraised different kinds of construction KPIs, criticizing most of them as mainly lagging and post event indicators. Using the EFQM Excellence Model criteria as a framework, they distinguished between three different types of indicators: i) KPIs, indicative of associated future performance, ii) Key Performance Outcomes (KPOs), as measures of completed actions and events and iii) Perception Measures, as individuals' judgements of leading or lagging measures, arguing that the developed CBPP headline KPIs basically represent KPOs. Dividing the five enabling Excellence Model criteria into two groups, they placed Processes in the first and the other four in the second, applying KPOs of Key Business Processes and sub-processes in the first and KPIs/ Perception Measures on the second. They proposed KPIs incorporated into a two-cycle PMS, the first involving measures implementation and the second initiating Change Action driven by Results, both of them based on the RADAR (Results, Approach, Deployment, Assessment and Review) logic of the EFQM.

Chan and Chan (2004) developed a framework for measuring success of construction projects, developing a set of KPIs, measured both objectively and subjectively, through a comprehensive literature review. Nine KPI categories in total were selected and divided into two groups, representing the objective and subjective measures respectively: the first one included the categories of Time, Cost, Value \& Profit, Health \& Safety and Environmental Performance and the second one the categories of Quality, Functionality, User expectation/satisfaction and Participants' satisfaction. In every category, they proposed a few, common used, representative KPIs.

Yu et al. (2007) established a PMS implementation model for construction companies, following a BSC approach and designing a set of benchmarking measures, serving as KPIs. Their model included a $P M$ framework, consisting of the four BSC perspectives, performance criteria and representative KPIs. They first identified 12 performance criteria, three for each BSC perspective, and formulated a candidate list of 45 initial indicators through literature review. Conducting a questionnaire survey in listed Korean construction companies and interviews with performance management experts, they cut down the initial list of indicators to 16 final KPIs.

Yeung et al. (2007), arguing that KPIs can serve as a benchmark for PM in construction partnering projects, developed a performance evaluation model of partnering projects in Hong Kong. Utilizing a previously developed KPIs' conceptual framework, they applied the Delphi survey technique, with a large number of construction experts, to rank and address weighs to the initial list, resulting in seven top-weighted KPIs. In addition, a composite Partnering Performance Index was derived to provide an integrated assessment of partnering performance. In a consequent study, Yeung et al. (2009), following a similar approach, formulated a model to evaluate the success of relationship-based construction projects in Australia, selecting this time eight KPIs, and calculated an equivalent Performance Index to assess their performance. In both studies, the developed indices were composed of a set of lagging KPIs.

Cha and Kim (2011) developed a framework for an effective PMS for building construction projects in South Korea, focusing on the project PM in the construction stage, 
from the perspective of the construction company. Deploying related literature analysis and implementing PMSs' cases, they identified eight candidate performance areas, which corresponded to the project objectives, and formed an initial list of 27 indicators. Throughout a preliminary review 6 categories and 20 indicators were screened out as potential KPIs and after an in-depth survey, examining their measurability and representativeness, they resulted to a final set of 18 KPIs.

Yeung et al. (2013) attempted to incorporate both leading and lagging KPIs, applying the Reliability Interval Method (RIM), to formulate a benchmarking model in order to assess project performance, at different stages of the project Life Cycle in Hong Kong. A list of KPIs was compiled, based on a comprehensive literature review, which was used to develop a survey questionnaire and the RIM was subsequently applied to analyse the survey results and determine the relative importance and rankings of the various leading and lagging KPIs. From the results, the top 10 KPIs were selected for the success evaluation of Hong Kong construction projects and a Composite Performance Index was derived to provide a comprehensive assessment.

\subsection{Summary characteristics of presented studies}

Cox et al. (2003), Chan \& Chan (2004), Yu et al. (2007) and Cha \& Kim (2011) identified, theoretically or empirically, indicators which can be applied for utilizing waste reduction. The proposed measures in the studies of Chan \& Chan and Yu et al. incorporated KPIs dealing with operations variability, while Chan \& Chan, Cha \& Kim and Yeung et al. (2013), adopting a pure KPIs framework, included a number of leading indicators examining functionality, equivalent to simplification of operations. Finally, all the presented PMSs contained a number of indices, grouped in various dimensions or categories, which can serve as benchmarking measures.

Table 1 summarizes the basic characteristics of the presented PMSs, reporting the corresponding LC principles to which each study has the most profound contribution.

Table 1: PMSs characteristics and LC principles contribution

\begin{tabular}{cccc}
\hline Author(s) $\quad$ (Year) & Approach followed & $\begin{array}{c}\text { PM framework } \\
\text { adopted }\end{array}$ & $\begin{array}{c}\text { LC principle } \\
\text { contribution }\end{array}$ \\
\hline Cox et al. (2003) & Empirical & KPI & $\mathrm{WR} / \mathrm{BN}$ \\
Beatham et al. (2004) & Conceptual/Empirical & EFQM/KPI & $\mathrm{BN}$ \\
Chan \& Chan (2004) & Conceptual & KPI & $\mathrm{WR} / \mathrm{VR} / \mathrm{OS} / \mathrm{BN}$ \\
Yu et al. (2007) & Conceptual/Empirical & BSC/KPI & $\mathrm{WR} / \mathrm{VR} / \mathrm{BN}$ \\
Yeung et al. (2007/2009) & Empirical & KPI & $\mathrm{BN}$ \\
Cha \& Kim (2011) & Empirical & KPI & $\mathrm{WR} / \mathrm{OS} / \mathrm{BN}$ \\
Yeung et al. (2013) & Empirical & KPI & OS/BN \\
\hline WR: Waste Reduction, VR: Varrability Reduction, OS: Operations Simplitication, BN: Benchmarking
\end{tabular}

Table 1 reveals that a common PM framework adopted in all the presented studies is KPIs, suggesting clearly that the use of indices in a PM framework is essential for the effective application of LC principles. In addition, from the four presented LC principles, the only one addressed in every study is benchmarking, indicating that PMSs developed for construction, support LC implementation basically through benchmarking. The next, 
most commonly, supported LC principle by the presented PMSs is waste reduction, appearing in four out of the seven reviewed studies.

\section{CONCLUSIONS}

The general trend of the PMSs in construction, reported in the literature during the last two decades, indicate that they can prove very useful in the implementation of LC. Such frameworks act as an indirect measurement of indicators and can provide valuable information, derived as a by-product of PMSs, which can be utilized to specific aspects of LC management. In this paper, a number of published studies were reviewed to substantiate the suggestion that the selection of appropriate PM measures has a major influence on the implementation of LC strategies. The use of PMSs based on contemporary PM frameworks, like the EFQM Excellence Model, the BSC and the KPIs, can assist the application of basic LC principles, such as such as waste and variability reduction, operations simplification and especially benchmarking. More specifically, the KPIs framework, used individually or in combination with the other two, is indispensable in the development of PMSs for these principles.

The increasing interest from the construction industry in PM models and frameworks provides a sound foundation for their use in conjunction with lean practices. Findings of this paper are based on wide implemented PM frameworks and a relative small number of published studies. As a future work, a more extensive literature review could be conducted, in order to include other PM frameworks and a larger sample of related studies.

\section{REFERENCES}

Alarcon, L.F., Grillo, A., Freire, J., and Diethelm, S. (2001). Learning From Collaborative Benchmarking in the Construction Industry. In: Proc. 9th Ann. Conf. of the Int'l. Group for Lean Construction, 6-8 August, Singapore, Singapore.

Bassioni, H.A., Price, A.D.F., and Hassan, T. M. (2004). Performance measurement in construction. ASCE J. of Manage.in Eng., 20(2), pp. 42-50.

Beatham, S., Anumba, C., Thorpe, T., and Hedges, I. (2004). KPIs: a critical appraisal of their use in construction. Benchmarking: An Int'l. J., 11(1), pp. 93-117.

Cha, H.S., and Kim, C.K. (2011). Quantitative Approach for Project Performance Measurement on Building Construction in South Korea. KSCE J. of Civil Eng., 15(8), pp. 1319-1328.

Chan, A.P.C., and Chan, A.P.L. (2004). Key performance indicators for measuring construction success. Benchmarking: An Int'l. J., 11(2), pp. 203-221.

Constructing Excellence (2006). Industry performance report 2006, CE, London, U.K.

Construction Industry Institute (2001). CII Benchmarking \& Metrics Data Report 2001, CII, Austin, Texas.

Costa, D.B., Formoso, C.T., Kagioglou, M., Alarcón, L.F. and Caldas, C.H. (2006). Benchmarking initiatives in the construction industry: Lessons learned and improvement opportunities. ASCE J. of Manage. in Eng., 22(4), pp. 158-167.

Cox, R.F., Issa, R.R.A., and Ahrens, D. (2003). Management's perception of key performance indicators for construction. ASCE J. Constr. Eng. Manage., 129(2), pp. 142-151.

European Foundation for Quality Management (1999). The EFQM Excellence Model (Blue Book). EFQM, Brussels, Belgium. British Quality Foundation, London, UK.

Egan, Sir, J. (1998). Rethinking Construction. Construction Task Force, Norwich, UK. 
Howell, G.A. (1999). What Is Lean Construction - 1999. In: Proc. $7^{\text {th }}$ Ann. Conf. of the Int'l. Group for Lean Construction, 26-28 July, Berkeley, USA, pp. 1-10.

Kaplan, R.S.,and Norton, D.P. (1992). The Balanced Scorecard - Measures that Drive Performance. Harvard Business Review, 70(1), pp. 71-79.

Kaplan, R.S.,and Norton, D.P. (1996). Using the Balanced Scorecard as a Strategic Management System. Harvard Business Review, 74(1), pp. 75-85.

Koskela, L. (1992). Application of the New Production Philosophy to Construction. Technical Report \#72, Center for Integrated Facility Engineering, Department of Civil Engineering, Stanford University.

Lantelme, E., and Formoso, C.T. (2000). Improving Performance Though Measurement: The Application of Lean Production \& Organisational Learning Principles. In: Proc. $8^{\text {th }}$ Ann. Conf. of the Int'l. Group for Lean Construction, 17-18 July, Brighton, UK.

Latham, Sir, M. (1994). Constructing The Team. Joint Review of Procurement \& Contractual Arrangements in the U.K. Construction Industry, London, UK: HMSO.

Manoliadis, O. (2011). Labour Productivity Benchmarking In Greek Projects. Organ., Tech. and Manage. in Constr. - An Int'l. J. 3(1), pp. 221-226.

Neely, A. (1999). The performance revolution: Why now and what next?. Int'l. J. of Operat. and Product. Manage., 19(2), pp. 205-228.

Sarhan, S, and Fox, A. (2013). Performance measurement in the UK construction industry and its role in supporting the application of lean construction concepts. Australasian J. of Constr. Econ. and Build., 13(1), pp. 23-35.

Thomas, H.R., Horman, M.J., de Souza, U.E.L., and Azvrski, I. (2002). Reducing variability to improve performance as a lean construction principle. ASCE J. of Constr. Eng. and Manage., 128(2), pp. 144-154.

Yang, H., Yeung, J.F.Y., Chan, A.P.C., Chiang, Y.H., and Chan, D.W.M. (2010). A critical review of performance measurement in construction. J. of Facil. Manage., 8(4), pp. 269284.

Yeung, J.F.Y., Chan, A.P.C., and Chan, D.W.M. (2009). Developing a performance index for relationship-based construction projects in Australia: Delphi study. ASCE J. of Manage. in Eng., 25(2), pp. 59-68.

Yeung, J.F.Y., Chan, A.P.C., Chan, D.W.M., Chiang, Y.H., and Yang, H. (2013). Developing a Benchmarking Model for Construction Projects in Hong Kong. ASCE J. of Constr. Eng. and Manage., 139(6), pp. 705-716.

Yeung, J.F.Y., Chan, A.P.C., Chan, D.W.M., and Li, L.K. (2007). Development of a partnering performance index (PPI) for construction projects in Hong Kong: a Delphi study. Constr. Manage. and Econ., 25(12), pp. 1219-1237.

Yu, I., Kim, K., Jung, Y., and Chin S. (2007). Comparable Performance Measurement System for Construction Companies. ASCE J. of Manage. in Eng., 23(3), pp. 131-139. 